\title{
LO QUE ITARD NO SE DEJA ENSEÑAR POR SU SALVAJE
}

\section{WHAT ITARD DOES NOT ALLOW HIMSELF TO LEARN FROM HIS SAVAGE BOY}

Fecha de recepción: 04/4/19 Fecha de aceptación: 14/4/19

\section{LÓPEZ STELLA M.}

Médico. Especialista jerarquizado en Psiquiatría infantil. Ex Jefa del Servicio de Salud Mental Hospital de Niños Sor María Ludovica de La Plata. JTP Clínica de Adultos y Gerontes, Facultad de Psicología, Universidad Nacional de La Plata (UNLP), Miembro de la Escuela de la Orientación Lacaniana (EOL) Sección La Plata y de La Asociación Mundial de Psicoanálisis (AMP).
Resumen: El caso del Salvaje de Aveyron bautizado Víctor resulta crucial para la ciencia del Iluminismo tardío.

En la época se debate la esencia del ser humano y el papel de la sociedad en el proceso de humanización. Para Pinel el Salvaje de Aveyron padece de idiotismo incurable.

Las memorias de Itard exponen el esfuerzo del médico-pedagogo para el desarrollo de las facultades del niño. La historia de un doctrinario que busca ilustrar con Víctor la estatua animada de Condillac.

Palabras clave: Salvaje - Pinel - Itard - Pedagogía - Lenguaje

A fines del Siglo XVIII fue encontrado un niño de aproximadamente 11 años trepado a los árboles en los bosques de La Caune, en la región francesa de Aveyron. El descubrimiento del salvaje despertó un vivo interés tanto en la sociedad como en las instituciones científicas de la época post revolucionaria en la Francia secular: la Sociedad de Observaciones sobre el hombre, el Hospicio de Bicêtre y la Escuela de reeducación para sordomudos de París.

Tras su captura un profesor de historia natural Pierre Bonnaterre en el Hospital de Rodez plan-
Abstract: The case of the Savageboy of Aveyron baptized as Victor is crucial for the science of Late Enlightenment.

At the time the essence of the human being and the role of society in the process of humanization are discussed. For Pinel the Savage boy of Aveyron suffers from incurable idiotism.

The memories of Itard expose the effort of the doctorpedagogue for the development of the faculties of the boy. The story of a doctrinaire who seeks to illustrate with Victor the animated statue of Condillac.

Key words: Savage. Pinel. Itard. Pedagogy. Language.

tea en un informe, la posibilidad de una evolución positiva de sus facultades intelectuales. Si bien el niño "no carece por completo de inteligencia ni de la capacidad de reflexionar y razonar", las mismas se limitan "a las funciones puramente animales"1. Solicita que el niño sea enviado a París para su estudio.

¿Cuál es el contexto que hace que el salvaje sea diferente a los otros niños encontrados abandonados? En la época polemizan teorías empiristas y racionalistas en lo tocante a la esencia del ser humano y el papel que juega la sociedad en el proceso de 
humanización. Este niño les abre un campo en torno al cual dirigir sus discusiones, experiencia decisiva del iluminismo tardío.

Con Víctor, la pedagogía, la psiquiatría y la psicología de los médicos filósofos se ponen a prueba. Si bien la constitución de la ciencia en base a datos y observaciones positivas; y la consideración unitaria y orgánica de lo físico seguían en pie; el debate acerca de la influencia del medio y el papel de la sociedad sobre el hombre natural adquirieron fuerte controversia.

El debate entre Pinel e Itard y publicaciones anónimas se suceden, herederos de Locke y Condillac, se oponen al innatismo de las ideas, paso decisivo, prescindiendo de la sociedad y la civilización para propender a la descripción y registro de las operaciones intelectuales y las facultades mentales en su relación con la experiencia sensible.

Cabanis se abalanza contra la estatua de su maestro Condillac "nada se parece menos al hombre que esa estatua, a la que se supone dotada de la facultad de probar de manera diferenciada las impresiones atribuidas a cada sentido en particular" 2 Cabanis subraya la unidad orgánica del ser humano, critica la concepción escotomizada de las sensaciones en la estatua de Condillac. Así también, entiende que "los sentidos deben ser remitidos a su interrelación" 3 . Los desarrollos de la concepción de la mente, abren el camino a la educación de Víctor y a una terapéutica que el maestro de Itard, realiza en la escuela de sordomudos.

En París las esperanzas más brillantes lo habían precedido, los curiosos se acercaban al hombre natural. ¿Qué encuentran científicos y legos? Un muchacho lleno de suciedad, propenso a movimientos espasmódicos y convulsivos, que mordía, indiferente a todo, emitía sonidos guturales inconexos, ojos huidizos, balanceándose lleno de excrementos.

¿Cómo aceptar en este espejo grotesco el otro originario? pronto los curiosos decepcionados ante el espectáculo lo abandonan. ¿Cómo reconocer en él el hombre libre sin palabras, que Rousseau desesperado por encontrar fue a buscar y soñó en su Emilio? El desdichado niño desarraigado del salvajismo e injertado en un mundo caótico para su observación objetiva, viene a encarnar el ideal del hombre no contaminado por la civilización, la estatua viviente de Condillac.

Pinel observador eminente, director de Bicêtreafirma: "nos alegramos de poder asistir a uno de los fenómenos que se presenta solo con grandes intervalos de tiempo y acerca de los cuales solo se poseen referencia vagas y subjetivas" 4 , poder estudiar la índole primitiva del hombre, conocer la serie de ideas y de sentimientos morales que son independientes del estado social. Analiza por separado los sentidos del niño comparándolo con los animales domesticados, los "escasos momentos de hilaridad vagos gritos agudos que animan su rostro" 5 resultan el fruto de una total ausencia de ideas. La carencia absoluta del don de la palabra, la falta de progreso sensible demostrada tras la estadía en el Instituto Nacional de sordomudos le permiten aseverar que como tantos otros muchachos cuyas funciones sensoriales o cuyas facultades mentales están más o menos lesionados está condenado a vegetar tristemente en un hospicio "a causa de un estado más o menos total de idiotismo o demencia", 6 y si ahora ingiere comida preparada, no ve en ello más que el resultado de la imitación y no la de un discernimiento bien educado 7. Advierte conla autoridad de su conocimiento, que en la época de la pubertad la violencia de los deseos se manifestará en"un muchacho poco susceptible a sentir afecto aun por las personas que lo ayudan" 8 . Concluye que el salvaje padece de idiotismo incurable y no es posible que la reeducación pueda restaurarle las facultades y los sentidos lesionados.

Para Pinel el niño estudiado fue abandonado porque se trataba de un caso de idiocia y no al revés. Itard en desacuerdo con Pinel se resiste a compartir sus tesis desfavorables. A los 26 años se le confía el niño en tanto mudo. Capta que ese no es el problema, sino más bien la soledad vivida en la selva. Nos ha legado sus Memorias del niño al que el bautizó como Víctor, de las cuales aún podemos extraer consecuencias. Se trata de las vicisitudes de ese lazo que Víctor como alumno más que como paciente e Itard más pedagogo que médico filósofo realizan. Para Jean Itard "no es en el hombre salvaje donde se encuentra el estado natural (...) Solo en el seno de la sociedad puede encontrar el nivel eminente que le ha sido asignado en la naturaleza"9. "El tipo de hombre realmente salvaje es aquel que no le debe nada a sus semejantes, en un estado de completo aislamiento individual." 10 Alberga Itard "que exista una alternativa más simple y sobre todo más humana de vincularlo a la vida social, antes de mandarlo al aburrimiento del hospicio."11 
Investido de su misión aplica su modelo pedagógico sin cuestionar la experiencia.

Se propone 5 objetivos principales de acuerdo a la posición doctrinaria: 1) Vincularlo a la vida social. 2) Despertar la sensibilidad nerviosa mediante estimulantes enérgicos y provocar de vez en cuando los afectos más vivaces del espíritu. 3) Ampliar su campo de ideas suscitándole nuevas necesidades multiplicando sus relaciones con los seres que lo rodeaban. 4) Inducirle al uso de la palabra determinando el ejercicio de la imitación a través de la imperiosa ley de la necesidad. 5) Ejercitar durante algún tiempo las operaciones más simples del espíritu sobre los objetos de sus necesidades físicas, ampliando luego la aplicación sobre objetos que pudieran instruirlo12.

En un ambiente que trataba "de utilizar con él buenas maneras y de tener mucha condescendencia con sus gustos y sus inclinaciones"13 él y la Sra. Guerin se hicieron cargo de hacerlo feliz a su manera. La Sra. Guerin es la encargada del cuidado especial del muchacho, lo hace con toda "la paciencia de una madre y con la inteligencia de una maestra iluminada" sin contrariar sus costumbres: dormir, comer, no hacer nada y correr por el campo.

Itard advierte que el cambio brusco en el niño de sensaciones ante los fenómenos naturales era vivo y clamoroso. De alegría al rodar por la nieve a tristeza ante el agua del estanque, capaz de despertarse si "los rayos lunares penetraban en su habitación." 14

Víctor indiferente al frío y al calor, es capaz de tomar con sus manos carbones que saltaban de los tizones ardientes. Se vuelve con su método cada vez más sensible al tacto, comienza a reconocer la temperatura del agua de baño negándose si la encuentra muy caliente. El procedimiento de dominio se extiende a la ropa, tras su uso Víctor se asusta ante su primer estornudo.

Llevado al campo al percibir el bosque y las colinas Víctor desea huir, su maestro decide no someterlo a pruebas semejantes $¿$ vuelve a buscar en esto el placer primitivo? es allí donde el niño ha adquirido un saber del que lo han separado. Itard fiel a sus nociones lo priva, el deseo debe reducirse a la necesidad.

Víctor ha desarrollado un afecto muy vivo por su gobernanta que lo testimonia de manera evidente Se separa de ella con dolor, la reencuentra con alegría, si esta le hace reproches Víctor comienza con una respiración dificultosa entrecortada, hasta lagrimea. Otros avances ocurren en las horas del recreo tanto con él como con la Sra. Guerin. Itard "se presta sin dificultades a estas niñerías." 15 Sin embargo pocas son las referencias a estos recreos pues no forman parte de la observación científica. ¿Por qué no habla si no es sordo? Se podía volver ante el ruido suave de una castaña pero "no podía apreciar la articulación de los sonidos" 16 Itard repara que la palabra es una especie de música a la que ciertos oídos pueden ser insensibles aunque estén bien articulados. Su plan se limita conforme a la noción de lenguaje de la época a inducirlo al uso de la palabra a través de la ley imperiosa de la necesidad. Así cuando se encontraba sediento le colocaba un vaso lleno de agua gritándole agua (eau en francés es o), entiende que la vocal primera sería la o Itard le acercaba el vaso de agua a otra persona cercana, pero el infeliz se atormentaba, emitía un chiflido, el salvaje era rebelde ante toda articulación vocal. No insistió, claro que con el mismo método procede con la letra ele, y logra que Víctor pronuncie lait/leche ante la presencia de la leche vertida, vana exclamación de alegría. Si la hubiera pronunciado antes de la concesión del objeto deseado, el objetivo se hubiera logrado "Víctor hubiera captado finalmente el significado verdadero de la palabra." 17 Itard confiesa en toda su simplicidad el lenguaje en acción. Este signo vital que surge en presencia, no es propiamente una palabra, no se articula a un pedido. El sonido aparece ante el goce de la cosa misma. Víctor usa otras vías para comunicar sus necesidades, así para conseguir una cuchara de lentejas da vuelta un cuadro redondo con vidrio, un plato muy especial.

La demanda queda a merced de la lectura del Otro, direccionalidad que acoge la Sra. Guerin como cuidadora y de la que Itard no puede, enfrascado en su saber, sacar más conclusiones.

El niño pronuncia la sílaba "Gli" hasta con dulzura incluso dormido, se trataba la silaba de Julie, el nombre de la hija de la gobernanta. El descubrimiento del nombre ocurre antes de la pubertad. Dado que la naturaleza de la palabra es solo profesar necesidades, para Itard no significa nada. Cada vez que se exclamaba cerca ¡Oh el Salvaje de Aveyron! Volvía la cabeza con fuerza, se comprueba la preferencia por la "O" lo que lo lleva a elegir para el muchacho el nombre Víctor, nombre de bautismo, ante el cual reacciona.

$\mathrm{Al}$ complejizarse la tarea, Víctor cansado responde 
coléricamente, esparce trozos de carbón en todo su dormitorio, Itard abre con violencia la ventana de su habitación, tomándolo con fuerza de las caderas le dirige la cabeza hacia el fondo del precipicio lo mete segundos después pálido, sudoroso, con los ojos lacrimosos, le exige ahí que recoja lo tirado. Luego de acatar llora abundantemente. Los episodios de llanto al abandonar a la gobernanta son posteriores a este incidente. Manera radical de introducir a Víctor en un vacío, una falta. Luego cada vez que lo obligaban a trabajar en horas de descanso apelaba a un murmullo de lamento. El despertar de la pubertad se manifiesta en forma explosiva lo lleva a Itard turbado a no apresurarse a juzgar pues estos "primeros fenómenos arrojan dudas sobre los orígenes de ciertos afectos del corazón que nosotros consideramos muy naturales." 18 Previamente se vio obligado a abolirle las fricciones en la espalda cuando estas no se limitaron a alegría y se extendieron a los órganos genitales.

Itard no extrae del balbuceo y del lenguaje de acción de Víctor más que la conclusión de su fracaso y abandona a su pupilo. Continuó como especialista en niños sordomudos. Constituye el germen de la reflexión médica sobre los niños con alteraciones y está en el origen de la llamada educación especial.

Notas

1. Montanari, A.: "Introducción", en El salvaje de Aveyron: pedagogía y psicología del iluminismo tardío, Centro Editor de América Latina S.A., Buenos Aires, 1978, pag 8.

2. Montanari, A: Ibídem, 1978, p. 13

3. Montanari, A: Ibídem, 1978, p.14

4. Pinel, P.: "Relación presentada ante la Societé des Observateurs de L'Homme sobre el niño conocido como el Salvaje de Aveyron" en El salvaje de Aveyron: pedagogía y psicología del iluminismo tardío, Centro Editor de América Latina S.A., Buenos Aires, 1978, p. 25

5. Pinel, P: Ibídem, 1978 p. 29

6. Pinel Ibídem, 1978 p.30

7. Pinel, P: Ibídem, 1978 p.37

8. Pinel, P: Ibídem, 1978 p.30

9. Itard, J: "Memoria sobre los primeros progresos de Víctor del Aveyron" en El salvaje de Aveyron: pedagogía y psicología del iluminismo tardio, Cen- tro Editor de América Latina S.A., Buenos Aires, 1978, p. 53

10. Itard J.: Ibídem, p. 54

11. Itard J.: Ibídem, p. 62

12. Itard J.: Ibídem, p. 61

13. Itard, J.: Ibídem, p. 63

14. Itard J.: Ibídem, p. 64

15. Itard J.: Ibídem, p. 73

16. Itard J.: Ibídem, p. 74

17. Itard J.: Ibídem, p. 78

18. Itard J.: Ibídem, p. 93

Bibliografía

-Mannoni, O.: "Itard y su salvaje", en La otra escena. Claves de lo imaginario, Amorrortu Editores, Buenos Aires, 1973.

- Pinel, P.; Itard,J.:El salvaje del Aveyron: pedagogía y psicología del Iluminismo tardío, Centro Editor de América Latina S.A.,Buenos Aires,1978. 